\title{
Chest physiotherapy and breathing exercises for cardiac surgery patients in Sweden - A National survey of practice
}

\author{
E. Westerdahl1,2,3, M. Fagevik Olsén4,5
}

\begin{abstract}
Chest physiotherapy and breathing exercises for cardiac surgery patients in Sweden - A National survey of practice. E. Westerdahl, M. Fagevik Olsén.

Background. Various chest physiotherapy techniques are recommended after cardiac surgery around the world. There is limited published data on what breathing exercises actually are recommended to patients after surgery in Europe. The aim of this national survey was to establish the current practice of chest physiotherapy and breathing exercises for adult patients following cardiac surgery in Sweden.

Methods. A postal questionnaire was sent to a total population sample of 33 Swedish physiotherapists working at the departments of cardiothoracic surgery in December 2007 and January 2008.
\end{abstract}

Results. In total, 29 replies $(88 \%)$ were received. Seven male and twenty two female physiotherapists completed the questionnaire. All physiotherapists instructed, on a regular basis, the cardiac surgery patients to perform post-operative breathing exercises. Positive expiratory pressure (PEP) breathing was routinely used as the first choice for treatment by $22(83 \%)$ of the physiotherapists. Expiratory pressures used varied between 2 and $20 \mathrm{~cm}$ $\mathrm{H}_{2} \mathrm{O}$. Recommended frequency and duration of the exercises varied from 4 to 30 breaths hourly during the daytime in the first post-operative days. All physiotherapists provided coughing support to the patients. Recommendations to continue breathing exercises after discharge varied from not at all up to 3 months after surgery.

Conclusions. Breathing exercises are regularly prescribed during the initial post-operative days after cardiac surgery in Sweden. Hourly deep breathing exercises performed with or without a PEP device were reported to be first choice treatments during the hospital stay. Instructions concerning how long patients should continue the exercises after discharge varied notably.

Monaldi Arch Chest Dis 2011; 75: 2, 112-119.

Keywords: Breathing exercises, Physiotherapy, Postoperative care, Questionnaire, Thoracic surgery.

1 Department of Cardiothoracic Surgery, Örebro University Hospital, Örebro,

2 School of Health and Medical Sciences, Örebro University, Örebro,

3 Department of Medical Sciences, Clinical Physiology, Uppsala University, Uppsala,

${ }^{4}$ Department of Physiotherapy, Sahlgrenska University Hospital, Gothenburg,

5 Institute for Neuroscience and Physiology, Sahlgrenska Academy, University of Gothenburg, Gothenburg, Sweden.

Funding: The Swedish Research Council, Reg. No. 2009-1385 and Uppsala University, Sweden funded this study.

Correspondence: PhD, RPT Elisabeth Westerdahl, Centre for Health Care Sciences, Örebro University Hospital, Box 1324, SE-701 13 Örebro, Sweden; e-mail: elisabeth.westerdahl@orebroll.se

\section{Introduction}

Chest physiotherapy and breathing exercises are often prescribed to patients undergoing cardiac surgery in order to prevent or reduce post-operative pulmonary complications. There is an agreement on the value of pre- and post-operative breathing exercises and physiotherapy treatment [1-4]. The literature contains examples of different breathing techniques with and without mechanical devices after cardiac surgery [3,5-7], but there is controversy regarding which breathing techniques are the most effective.

Surveys describing chest physiotherapy management of patients undergoing cardiac surgery have been carried out in Australia and New Zealand [8] and in Canada [9]. The use of positive pressure devices during hospitalisation in Brazil has also recently been presented [10]. It appears to be various recommendations of breathing exercises for patients undergoing cardiac surgery around the world. To date, no survey describing the use of post-operative breathing exercises for cardiac surgery patients in Europe has been carried out.

The aim of the present study was to determine current physiotherapy practice regarding breathing exercises for patients undergoing cardiac surgery in Sweden.

\section{Methods}

The study design was a national postal questionnaire survey to all physiotherapists working at the departments of cardiothoracic surgery in Sweden. The survey applied to chest physiotherapy treatment of adult patients undergoing uncomplicated cardiac surgery including coronary artery bypass grafting (CABG), mitral, aortic, and tricus- 
pid valve surgery, or a combination of these, including off- pump surgery. To determine the standard clinical practice, routine pre- and post-operative care of a hypothetical, "everyday patient" was considered. The care of patients developing complications or other conditions requiring individualised treatment was not considered. Physiotherapists only treating children or adult patients undergoing other types of surgical procedures were asked to return the questionnaire unanswered.

A total population sample of 33 physiotherapists working at the departments of cardiothoracic surgery in Sweden during December 2007 and January 2008 was identified. The hospitals performed cardiac surgery, with a range from 310 to 1,635 operations per year during 2007. The average physiotherapy staffing level was 3.2 (range 15) full-time equivalents. The median length of post-operative hospital stay for the cardiac surgery patients was 9 days.

The questionnaire was developed for this specific study, and was based on a detailed review of the literature and previously developed questionnaires [8, 9]. Suitable items were selected and modified to Swedish conditions as necessary. Structured and open-ended questions were asked about routine care of patients undergoing cardiac surgery. The questionnaire consisted of questions on pre- and post-operative physiotherapy treatment. The research focus had two aspects; mobilisation and range of motion exercises [11], and breathing exercises, presented in this paper (appendix 1).

The author identified the names and addresses of the respondents during a Swedish Thoracic Society meeting in October 2007. The names were cross-checked via phone or mail by the author at each hospital immediately prior to start to the study start, and in total 36 physiotherapists were identified. The questionnaire was addressed personally to the physiotherapists identified. A covering letter and a prepaid response envelope were included with each questionnaire. A reminder letter and another copy of the questionnaire were sent after 2-3 weeks, if the questionnaire had not been returned.

The Regional Ethics Review Board was consulted, before the start of the study, and the board advised that no formal ethical approval was required. The lead clinician of each cardiothoracic department at the selected hospitals was contacted by e-mail to obtain permission to carry out the study. Written informed consent was obtained granting permission for their physiotherapists to participate in the study.

Data was analysed using descriptive statistics, and the mean, median, and range were calculated. The SPSS version 15.0 software package (SPSS Inc, Chicago, IL) was used for the statistical analysis.

\section{Results}

Responses were received from physiotherapists at all 8 hospitals to which the survey was sent. Three of the 36 identified physiotherapists were not included in the study because they were on parental leave or were not longer working with the actual patient group. In total, 29 replies were received out of the 33 questionnaires sent out, giving a response rate of $88 \%$.

Seven male and twenty two female physiotherapists aged $41 \pm 8$ (range 27-59) years answered the questionnaire. The total mean work experience as a physiotherapist was $10 \pm 7$ (range 1-33) years, and the mean work time at a department of cardiothoracic surgery was $6 \pm 4$ (range 1-16) years. Twenty-one $(72 \%)$ of the respondents had completed specific courses in the cardiopulmonary area.

In total, $23(88 \%)$ physiotherapists informed the patients pre-operatively about breathing exercises and coughing techniques, and 19 (73\%) had asked the patients to practice the techniques preoperatively. Identification of patients at high risk for postoperative pulmonary complications was noted by $16(62 \%)$ of the physiotherapists preoperatively. The risk factors mentioned were as follows; obstructive and/or restrictive lung disease (n $=16)$, overweight $(\mathrm{n}=12)$, current smoking $(\mathrm{n}=$ $10)$, decreased physical activity ability $(n=7)$, high age $(n=5)$, secretion problems $(n=4)$, dementia $(n=2)$, diabetes $(n=1)$ and neurological disease $(n=1)$.

Chest physiotherapy treatment was routinely given to the patients, at the thoracic intensive care unit (ICU), during the first post-operative morning after surgery. Twenty of the physiotherapists had experience from working in the ICU. Written guidelines or protocols for the physiotherapy treatment of extubated patients in the ICU were available according to 14 of the respondents, whereas physiotherapy guidelines for intubated patients were less accessible $(n=4)$. Two of the physiotherapists performed manual hyperinflation of the lungs, 7 performed suction of airways via nose, mouth, or tracheotomy, and 5 actively participated in the procedure for weaning a patient off the respirator.

During the initial post-operative days the patients usually received 1 to 3 treatment sessions a day by the physiotherapist (table 1). Treatment given is presented in table 2 .

Detailed information on postoperative mobilization, range of motion exercises, and sternal precautions has been published previously [11].

Coughing support was provided to the patients, according to all 29 physiotherapists. Several methods were used: patient performance with a small pillow, without a pillow, manual support from the physiotherapist, or sternal support with a device such as the Heart Hugger harness.

All of the physiotherapists instructed the patients to perform breathing exercises on a regular basis post-operatively. Breathing exercises usually provided to the patients on the first postoperative days after surgery are presented in table 3 . The two most frequently used breathing techniques were positive expiratory pressure (PEP) device breathing and deep breathing performed without any mechanical device. PEP device breathing was routinely used as first choice treatment by treatment by $24(83 \%)$ of the respondents. Expiratory pres- 
Table 1. - Average physiotherapy treatment sessions given to cardiac surgery patients during the first five postoperative days

\begin{tabular}{lccc}
\hline Treatment on: & PT Given routinely & PT given if needed & Treatment sessions/day \\
\hline Day of surgery & $1(3 \%)$ & $10(35 \%)$ & 1 \\
POD 1 & $26(90 \%)$ & $1(3 \%)$ & $1-3$ \\
POD 2 & $27(93 \%)$ & $1(3 \%)$ & $1-2$ \\
POD 3 & $20(69 \%)$ & $8(28 \%)$ & $1-2$ \\
POD 4 & $8(28 \%)$ & $20(69 \%)$ & 1 \\
POD 5 & $8(28 \%)$ & $20(69 \%)$ & 1 \\
\hline
\end{tabular}

Data are presented as the number (and percentage) of physiotherapists $(n=29)$. Routines apply to ordinary practice Monday to Friday. Abbreviations: PT: physiotherapy, POD: postoperative day.

sures used for PEP treatment was in the range of 2 to $20 \mathrm{~cm} \mathrm{H}_{2} \mathrm{O}$. The instruction to the patient on how to perform the breathing exercises with the PEP device (mask, mouth-piece, or blow bottle) was almost identical for 19 of the physiotherapists, who told the patients to perform deep inspiration, and after that perform a slightly forced expiration through the PEP device without emptying the lungs, to avoid airway closure. Of these 19 physiotherapists, 3 in addition taught the patients to perform an inspiratory hold at maximal lung volume during the deep breathing. Two respondents answered that the instruction was individualised for each patient, and 2 reported that the instruction was to perform quiet breathing, while 6 physiotherapists did not answer this question.

All physiotherapists except one instructed the patients to perform the recommended breathing exercises once an hour during the first two postoperative days. The number of breaths that the patients were instructed to perform at each training session during the first two post-operative days varied; $10 \times 3$ breaths $(\mathrm{n}=21), 20 \times 2$ breaths $(\mathrm{n}=$ $3), 10$ breaths $(n=4), 4-5$ breaths hourly $(n=1)$. During the rest of the hospital stay, 19 physiotherapists recommended the same training frequency and duration as during the first two post-operative days, 3 gave other instructions depending on the mobilisation grade and 7 did not answer.

Instructions to the patients to continue breathing exercises after discharge varied considerably, from no instructions $(n=6)$, continue when indicated $(n=9)$, continue for an unspecified time a day $(n=9)$, or instructions to quit at discharge $(\mathrm{n}=2)$. The most frequently recommended device for the patients to take home was a PEP device/ mouthpiece $(n=10)$ or a blow bottle $(n=8)$. One physiotherapist suggested pursed lips breathing after discharge. After discharge the patients were recommended to continue the breathing exercises with varying duration from not at all up to three months post-operatively.

\section{Discussion}

This is the first national survey in Europe to describe the use of breathing exercises after cardiac surgery. Chest physiotherapy practice in Sweden has many similarities to other international surveys of clinical practice [8-10]. Several breathing exercises are applied, besides early mobilisation. In the present study, all physiotherapists instructed the patients to perform breathing exercises, with or without PEP, on a regular basis postoperatively. Deep breathing exercises was the first choice of breathing technique and this in agreement with the results from Overend et al. [9], who demonstrated that treatment the first postoperative days primarily consisted of deep breathing exercises and coughing. The earlier study by Tucker $e t$ al. [8] performed in Australia and New Zealand in the 90's, also demonstrated that deep breathing exercises was the most commonly used technique.

The use of breathing exercises with positive pressure devices is used extensively in clinical practice post-operatively in Brazil [10] and after thoracic surgery in Australia and New Zealand [12], despite the lack of evidence of benefit com-

Table 2. - Usual chest physiotherapy treatments given to cardiac surgery patients during the first four post-operative days

\begin{tabular}{lcccc}
\hline & POD 1 & POD 2 & POD 3 & POD 4 \\
\hline Breathing exercises & $28(97 \%)$ & $26(90 \%)$ & $18(62 \%)$ & $13(45 \%)$ \\
Chest wall vibrations, percussions & $0(0 \%)$ & $0(0 \%)$ & $0(0 \%)$ & $0(0 \%)$ \\
Coughing/huffing techniques & $27(93 \%)$ & $25(86 \%)$ & $17(59 \%)$ & $13(45 \%)$ \\
Positioning, lying on side & $7(24 \%)$ & $8(28 \%)$ & $3(10 \%)$ & $3(10 \%)$ \\
Postural drainage & $0(0 \%)$ & $0(0 \%)$ & $0(0 \%)$ & $0(0 \%)$ \\
Relaxation techniques & $4(14 \%)$ & $4(14 \%)$ & $2(7 \%)$ & $1(3 \%)$ \\
\hline
\end{tabular}

Data are presented as the number (and percentage) of physiotherapists $(n=29)$.

Abbreviations: POD: post-operative day. 
Table 3. - Specific breathing exercises given to cardiac surgery patients during the initial post-operative days

\begin{tabular}{lcccc}
\hline & Routinely & If needed & Never & Missing \\
\hline Deep breathing exercises & $18(62 \%)$ & $8(28 \%)$ & $1(3 \%)$ & $2(7 \%)$ \\
Diaphragmatic breathing & $11(38 \%)$ & $11(38 \%)$ & $3(10 \%)$ & $4(14 \%)$ \\
Pursed lip breathing & $6(21 \%)$ & $18(62 \%)$ & $1(3 \%)$ & $4(14 \%)$ \\
Sustained maximal inspiration & $3(10 \%)$ & $1(3 \%)$ & $21(72 \%)$ & $4(14 \%)$ \\
Incentive spirometry & $5(17 \%)$ & $21(72 \%)$ & $0(0 \%)$ & $3(10 \%)$ \\
PEP device breathing & $24(83 \%)$ & $4(14 \%)$ & $0(0 \%)$ & $1(3 \%)$ \\
IR-PEP & $7(24 \%)$ & $9(31 \%)$ & $12(41 \%)$ & $1(3 \%)$ \\
IMT & $6(21 \%)$ & $20(69 \%)$ & $0(0 \%)$ & $3(10 \%)$ \\
CPAP & $0(0 \%)$ & $26(90 \%)$ & $2(7 \%)$ & $1(3 \%)$ \\
\hline
\end{tabular}

Data is presented as the number (and percentage) of physiotherapists $(n=29)$.

Abbreviations: CPAP: continuous positive airway pressure, IMT: Inspiratory muscle training, IR-PEP: inspiratory resistancepositive expiratory pressure, PEP: positive expiratory pressure.

pared with that for conventional breathing exercises [13-16]. To visualise and facilitate inspiration the Incentive spirometry device is often recommended as treatment in other countries [8,9], but is seldom used in Sweden. The optimal technique is not established, and there are presently no systematic reviews on the most favourable breathing technique after cardiac surgery.

Breathing exercises were applied once per hour for the first two post-operative days, while repetitions at each training session varied between 4 and 30 breaths during the first post-operative days. There is no agreement on how often breathing exercises should be performed, but the physiotherapists' most commonly recommendation of hourly treatment in the present study, is consistent with the current literature on the suggested frequency $[1,17,18]$.

Different hospital policy, of course, dictates how clinical practice is performed, but to compare routines at different hospitals was not the focus in the present survey. The organisation of physiotherapy treatment and rehabilitation programmes differs between countries, which could limit the applicability and comparison to other countries [19]. Post-operative care is, moreover, an interdisciplinary approach, and many therapies are applied by the personal staff, which plays an important role in post-operative care, however, other professional categories were likewise not the focus in this survey.

The number of respondents was rather small, although representing all cardiac surgical units in Sweden. A response rate of $88 \%$ can be considered high. Various strategies were employed to achieve the high response rate. Cover letters were included with the questionnaires, clear instructions were given, and reminders were sent out if questionnaires had not been returned [20]. Responses were received from physiotherapists at all hospitals to which the survey was sent, and the total population sample gives the study good external validity. We believe that this survey provides a representative illustration of how chest physiotherapy treatment of cardiac surgery patients is carried out in Swe- den. However, no validated questionnaire was used, the inquiry was comprehensive, and selection or reporting bias may have influenced the validity. Despite these limitations, we believe that the results from this survey could reflect current clinical practice.

Post-operative complications are relatively frequent after cardiac surgery. It has earlier been suggested that breathing exercises after uncomplicated cardiac surgery confers no extra benefit [21, 22]. Since then, several articles showing the effect of both pre- and postoperative chest physiotherapy techniques have been published $[1,2,4,15]$. However, there is currently no evidence to support one breathing technique over another [6, 15, 23, 24].

In summary, this study provides an overview of current practice regarding postoperative breathing exercises recommended to cardiac surgery patients in Sweden. All physiotherapists regularly advised postoperative breathing exercises. The two most frequently used techniques were deep breathing with a PEP device and deep breathing without a device. The breathing exercises were most often performed hourly. Recommended repetitions at each training session varied considerably and inconsistent recommendations to continue breathing exercises after discharge was given. This study raises further questions about the best way to treat these patients and highlights the need for future research to optimise physiotherapy treatment following cardiac surgery.

In many hospitals, chest physiotherapy is routinely offered after cardiac surgery. If the practice is uniform among all physiotherapists in each unit is furthermore important to consider. There are various treatment options and opinions about the best way to treat the patients, and this survey indicates the need for internationally approved guidelines to establish the optimal content and timing of post-operative breathing exercises.

Acknowledgements: We thank Tom Overend, Associate Professor, University of Western Ontario, Toronto, Canada, for help to design the questionnaire. The Swedish Research Council, Reg. No. 2009-1385 and Uppsala University, Sweden funded this study. 


\section{References}

1. Westerdahl E, Lindmark B, Eriksson T, Friberg O, Hedenstierna G, Tenling A. Deep-breathing exercises reduce atelectasis and improve pulmonary function after coronary artery bypass surgery. Chest 2005; 128 : 3482-8.

2. Hulzebos EH, Helders PJ, Favie NJ, et al. Preoperative intensive inspiratory muscle training to prevent postoperative pulmonary complications in high-risk patients undergoing $\mathrm{CABG}$ surgery: a randomized clinical trial. JAMA 2006; 18; 296: 1851-7.

3. Haeffener MP, Ferreira GM, Barreto SS, Arena R, Dall'Ago P. Incentive spirometry with expiratory positive airway pressure reduces pulmonary complications, improves pulmonary function and 6-minute walk distance in patients undergoing coronary artery bypass graft surgery. Am Heart J 2008; 156: 900.

4. Herdy AH, Marcchi PLB, Vila A, et al. Pre- and postoperative cardiopulmonary rehabilitation in hospitalized patients undergoing coronary artery bypass surgery: A randomized controlled trial. Am J Phys Med Rehabil 2008; 87: 714-9.

5. Zarbock A, Mueller E, Netzer S, Gabriel A, Feindt P, Kindgen-Milles D. Prophylactic nasal continuous positive airway pressure following cardiac surgery protects from postoperative pulmonary complications: a prospective, randomized, controlled trial in 500 patients. Chest 2009; 135: 1252-9.

6. Renault JA, Costa-Val R, Rosseti MB, Houri Neto M. Comparison between deep breathing exercises and incentive spirometry after CABG surgery. Rev Bras Cir Cardiovasc 2009; 24: 165-72.

7. Agostini P, Singh S. Incentive spirometry following thoracic surgery: What should we be doing? Physiotherapy 2009; 95: 76-82.

8. Tucker B, Jenkins S, Davies K, McGann R, Waddell J, King R. The physiotherapy management of patients undergoing coronary artery surgery: A questionnaire survey. Aust J Physiother 1996; 42: 129-37.

9. Overend TJ, Anderson CM, Jackson J, Lucy SD, Prendergast M, Sinclair S. Physical therapy management for adult patients undergoing cardiac surgery: A Canadian practice survey. Physiother Can 2010; 62: 215-21.

10. Fiore JF, Chiavegato LD, Paisani DM, Colucci DB. Utilization of positive-pressure devices for breathing exercises in the hospital setting: A regional survey in Sao Paulo, Brazil. Respir Care 2010; 55: 719-24.

11. Westerdahl E, Moller M. Physiotherapy-supervised mobilization and exercise following cardiac surgery: a national questionnaire survey in Sweden. $J$ Cardiothorac Surg 2010 25; 5: 67.

12. Reeve J, Denehy L, Stiller K. The physiotherapy management of patients undergoing thoracic surgery: A sur- vey of current practice in Australia and New Zealand. Physiother Res Int 2007; 12: 59-71.

13. Ingwersen UM, Larsen KR, Bertelsen MT, et al. Three different mask physiotherapy regimens for prevention of post- operative pulmonary complications after heart and pulmonary surgery. Intensive Care Med 1993; 19: 294-8.

14. Richter Larsen K, Ingwersen U, Thode S, Jakobsen S. Mask physiotherapy in patients after heart surgery: A controlled study. Intensive Care Med 1995; 21: 469-74.

15. Westerdahl E, Lindmark B, Eriksson T, Hedenstierna $\mathrm{G}$, Tenling A. The immediate effects of deep breathing exercises on atelectasis and oxygenation after cardiac surgery. Scand Cardiovasc J 2003; 37: 363-7.

16. Borghi-Silva A, Mendes RG, Costa Fde S, Di Lorenzo VA, Oliveira CR, Luzzi S. The influences of positive end expiratory pressure (PEEP) associated with physiotherapy intervention in phase I cardiac rehabilitation. Clinics 2005; 60: 465-72.

17. Muller AP, Olandoski M, Macedo R, Costantini C, Guarita-Souza LC. Comparative study between intermittent (Muller Reanimator) and continuous positive airway pressure in the postoperative period of coronary artery bypass grafting. Arq Bras Cardiol 2006; 86: 232-9.

18. Yanez-Brage I, Pita-Fernandez S, Juffe-Stein A, Martinez-Gonzalez U, Pertega-Diaz S, Mauleon-Garcia A. Respiratory physiotherapy and incidence of pulmonary complications in off-pump coronary artery bypass graft surgery: An observational follow-up study. BMC Pulm Med 2009; 9: 36.

19. Griffo R, Fattirolli F, Temporelli PL, Tramarin R. Italian survey on cardiac rehabilitation and secondary prevention after cardiac revascularization: ICAROS study. A survey from the Italian cardiac rehabilitation network: rationale and design. Monaldi Arch Chest Dis 2008; 70: 99-104, 6.

20. Edwards PJ, Roberts I, Clarke MJ, et al. Methods to increase response to postal and electronic questionnaires. Cochrane Database Syst Rev 2009 (3): MR000008.

21. Jenkins SC, Soutar SA, Loukota JM, Johnson LC, Moxham J. Physiotherapy after coronary artery surgery: are breathing exercises necessary? Thorax 1989; 44: 634-9.

22. Stiller K, Montarello J, Wallace M, et al. Efficacy of breathing and coughing exercises in the prevention of pulmonary complications after coronary artery surgery. Chest 1994; 105: 741-7.

23. Pasquina P, Merlani P, Granier JM, Ricou B. Continuous positive airway pressure versus noninvasive pressure support ventilation to treat atelectasis after cardiac surgery. Anesth Analg 2004; 99: 1001-8.

24. Savci S, Sakinc S, Ince DI, et al. Active cycle of breathing techniques and incentive spirometer in coronary artery bypass graft surgery. Fizyoterapi Rehabilitasyon 2006; 17: 61-9. 
Appendix 1

\section{QUESTIONNAIRE}

This survey only applies to physiotherapy treatment of adult patients who have undergone cardiac surgery (coronary artery bypass graft surgery $(\mathrm{CABG})$, mitral, aortic or tricuspid valve surgery, or a combination of CABG \& valve surgery, including off- pump surgery).

We would like to investigate routine postoperative physiotherapy management (with focus on breathing exercises) of patients undergoing uncomplicated open-heart surgery. Patients who develop neurological symptoms, circulatory instability, prolonged intubation, or other conditions requiring individualised programmes are not included. If you only treat patients who have undergone other types of cardiac, pulmonary or thoracic surgery procedures and cannot answer these questions, please return this questionnaire unanswered.

Are you male or female?

$$
\begin{array}{ll}
\square & \text { Female } \\
\square & \text { Male }
\end{array}
$$

In what year were you born? 19

How many years have you been working as a physiotherapist?

How long (years or months) have you been working as physiotherapist in a Thoracic Surgery Department?

Have you completed any specific courses in the cardiopulmonary area (courses for credits and other courses)?

$$
\begin{array}{ll}
\square & \text { No } \\
\square & \text { Yes }
\end{array}
$$

Do all patients undergoing open-heart surgery (non-emergency) at your Thoracic Surgery Department usually receive preoperative information from a physiotherapist?

$$
\begin{array}{ll}
\square & \text { No } \\
\square & \text { Yes }
\end{array}
$$

What is included in the physiotherapist's preoperative information? (check as many as apply)

$$
\text { Oral information Practical review }
$$

Surgical procedure in general

Sternotomy (opening/closure, postop restrictions)

Respirator treatment/extubation

Postoperative pulmonary function/ complications

Breathing exercises

Coughing/huffing technique

Do you as a physiotherapist preoperatively identify patients at high risk for postoperative pulmonary complications?

$$
\begin{array}{ll}
\square & \text { No } \\
\square & \text { Yes }
\end{array}
$$

Do patients who have undergone cardiac surgery usually receive physiotherapy in the Thoracic ICU on postoperative day 1? (Monday to Friday)

$$
\begin{array}{ll}
\square & \text { No } \\
\square & \text { Only certain patients } \\
\square & \text { Yes, all patients }
\end{array}
$$

Are there written guidelines or protocol for usual physiotherapy management of normal intubated patients who have undergone cardiac surgery?

ㄱo

Yes - If yes please send us a copy 
Are there written physiotherapy guidelines or protocol for usual physiotherapy management of extubated patients who have had cardiac surgery?

$$
\begin{array}{ll}
\text { ㅁ } & \text { No } \\
& \text { Yes - If yes, please send us a copy }
\end{array}
$$

Do you perform manual hyperinflation/bagging?

$$
\begin{array}{ll}
\square & \text { No } \\
\square & \text { Yes }
\end{array}
$$

Do you perform suction of airways via nose, mouth or tracheostomy?

$$
\begin{array}{ll}
\square & \text { No } \\
\square & \text { Yes }
\end{array}
$$

Do you participate actively in weaning off respirator?

$$
\begin{array}{ll}
\square & \text { No } \\
\square & \text { Yes }
\end{array}
$$

Which of the following days do you or your colleagues usually treat patients and on average how many sessions does the patient receive per day? (ordinary routines Monday to Friday)

Treatment on: $\quad$ Routinely If needed Never
Day of surgery Day 0
Postoperative day 1
Postoperative day 2
Postoperative day 3
Postoperative day 4
Postoperative day 5

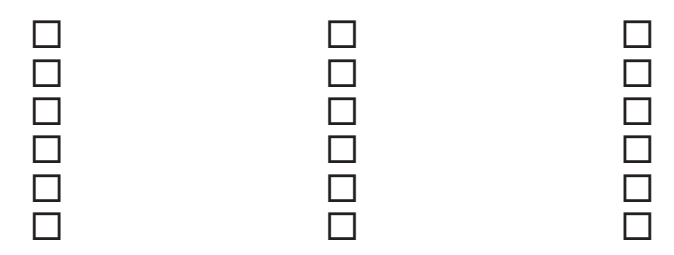

Check the box of the following treatments you usually provide to the patient on the first four postoperative days after surgery? $(\mathrm{POD}=$ postoperative day)

$$
\begin{array}{llll}
\text { POD } 1 & \text { POD } 2 & \text { POD } 3 & \text { POD4 }
\end{array}
$$

Breathing exercises

Coughing/huffing techniques

Chest wall vibrations, percussions

Positioning, side lying

Postural drainage

Relaxation techniques

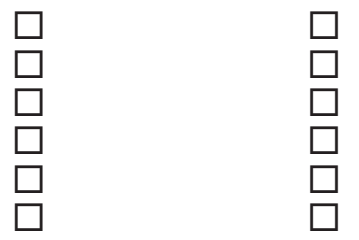

Are patients instructed to perform breathing exercises on a regular basis postoperatively?

$$
\square \text { No }
$$

If so, what kind of breathing exercises are patients instructed to perform? (Check as many as apply)

Deep breathing exercises

Diaphragmatic breathing

Pursed lip breathing

Sustained (continual) maximal inspiration

Incentive spirometry (Voldyne, Triflo etc)

PEP (positive expiratory pressure) device breathing

IR-PEP (inspiratory resistance-PEP)

IMT (inspiratory muscle training) . $\mathrm{cm} \mathrm{H}_{2} \mathrm{O}$

CPAP cm $\mathrm{H}_{2} \mathrm{O}$

Routinely If needed Never Missing

Other

$\begin{array}{llll}\square & \square & \square & \square \\ \square & \square & \square & \square \\ \square & \square & \square & \square \\ \square & \square & \square & \square \\ \square & \square & \square & \square \\ \square & \square & \square & \square \\ \square & \square & \square & \square \\ \square & \square & \square & \square \\ \square & \square & \square & \square \\ \square & \square & \square & \square\end{array}$


If PEP breathing is used, please specify the device and pressure used (lowest/highest).

$\mathrm{PEP}$ mask/valve (Astra tech)

Blow bottle

Flutter

Breathing exerciser (Rium/Dolema)

Pursed lip breathing

Other

Please describe how you instruct patients to perform the breathing exercises

How many times per day are patients usually instructed to perform the suggested breathing ?

Day 1

Day 2

Day 3 to discharge.

After discharge from the Thoracic Surgery department/at home

How many breaths are patients instructed to perform at each training session?

If a patient has secretion problems, do you provide coughing support to the patient?

․ No

Yes - If yes, check the techniques that are used:

Manually, patient performance with a small pillow

Manually, patent performance without a pillow

Manually by physiotherapist

- Sternal support with device, e.g. Heart Hugger

Other

Do you recommend that patients continue performing breathing exercises at home after discharge from the Thoracic Surgery department?
ㄱo
口 Yes

If yes, what type of breathing exercises do you usually recommend that patients do (frequency and duration)?

If so, do you send a device home with the patient for the breathing exercises?

$\begin{array}{ll}\square & \text { No } \\ \square & \text { Yes }\end{array}$

For how long after discharge do you normally recommend that patients continue their breathing exercises? 